International Journal of Engineering \& Technology, 7 (3.27) (2018) $471-475$
International Journal of Engineering \& Technology
WPC
Website: www.sciencepubco.com/index.php/IJET
Research paper

\title{
Design of an Ultra-Wideband Antenna for Breast Cancer Detection
}

\author{
C. Jayapriya $^{1 *}$, K. Meena Alias Jeyanthi ${ }^{2}$ \\ ${ }^{1}$ PG Scholar, Department of Electronics and Communication Engineering, PSNA College of Engineering and Technology, Dindigul, \\ Tamil Nadu, India. \\ ${ }^{2}$ Professor, Department of Electronics and Communication Engineering, PSNA College of Engineering and Technology, Dindigul, Tamil \\ Nadu, India.
}

\begin{abstract}
Ultra Wideband (UWB) radar is assuring technology for breast cancer detection based on the dielectric constant between normal and tumor tissues at Microwave frequencies. A Suitable design of a Microstrip Patch in Ultrawideband is proposed for microwave imaging in biomedical applications. Currently used clinical diagnostic methods, such as X-ray Mammography, Ultra-Sound and Magnetic Resonance Imaging, are limited by cost and reliability issues. These limitations have motivated researchers to develop a more effective, low-cost diagnostic method and involving lower ionization for cancer detection. The literature suggests a Side Slotted Vivaldi Antenna (SSVA) is clustered around $2.4 \mathrm{GHz}$ as the ISM band which is used for breast phantom measurement. Experimental validation is done mainly by using an antenna for detecting tumor cells inside a breast which is highly demanded as comfortable approach.
\end{abstract}

Keywords: ADS software, breast phantom measurement, microwave imaging, slotted vivaldi antenna.

\section{Introduction}

Bosom malignancy is that the commonest growth in young ladies, anyway as it would turn out early identification and treatment will significantly enhance the survival rate. carcinoma represents twenty 6th of every female patient tormented by growth inside the us, wherever consistently, 182,000 cases ar analyzed and additionally so twenty second of those cases end in death. The key factors in up survival rates and nature of lifetime of disease patients are: solid diagnosing for early discovery, early mediation and dependable viewing. Microwave imaging could be another innovation that has potential applications inside the field of symptomatic prescription. when presented to microwaves, the high water substance of tumorous bosom tissues cause significant microwave scrambling and its permittivity appears with entirely unexpected assimilation and dissipating rates. on account of the enhanced protector refinement, higher tissue portrayal too is plausible. Ultrasound, indicative methodology and reverberation Imaging (MRI) ar directly utilized clinically for carcinoma diagnosing. These procedures have a few impediments, similar to high rate of uncomprehensible recognitions, radiation (mammography), too expensive to be in any way wide offered, et cetera. Being noninvasive, abuse non-ionizing fluctuate of attractive power waves and maintaining a strategic distance from difficult bosom pressure construct this procedure a great deal of advantageous as a screening apparatuses. The fiddler gathering hardware itself contains just of the deprecated hole, which may be thought of as a two-dimensional exponential horn. The nourishing of the recieving wire is on the thin feature space. the elective feature to the pillar bearing is shortcircuited by a stub. on account of bigger data measure this reception apparatus frame is suitable for ultrawide band applications. amid this paper, a changed SSVA with expanded resistivity data measure especially for bosom apparition measure, is given. Six spaces ar recorded out of the disparate balances to expand the viable electrical length and produce more grounded order radiation and conjointly it upgrades the pick up to broaden the recieving wire data measure. Reproduction and estimated comes about demonstrate that the anticipated reception apparatus will get the data measure from one.54 to seven gigacycle for every second with relate degree similarly dispersed current appropriation and an amazingly order stable.

\section{Description of the Antenna Structure}

Vivaldi radio wire is a sort of decreased space reception apparatus with broadband, which have the upsides of high increase, light weight, minimized size, wide impedance transmission capacity and it is directly enraptured. This decreased space is mounted on a dielectric substrate which is mounted on ground plane. The geometric format and manufactured model of the proposed recieving wire are appeared in Figure 1. The recieving wire is created on a Rogers RT/duroid 5870 substrate with a substrate thickness of $1.57 \mathrm{~mm}$ and its relative permittivity isobserved as 2.33 and misfortune digression of 0.0012. The lower spaces (S1, S2, and S3) change as the higher request openings are diminished by $2 \mathrm{~mm}$ in hole and stature. The upper spaces S4 and S5 are symmetric, yet the last is diminished by $4 \mathrm{~mm}$. To accomplish a bigger working transmission capacity, a microstrip space with an outspread stub is presented. The stub starts at 450, with an aggregate scope stub-point of $\varphi=900$ and a range of $\mathrm{R} 1=10 \mathrm{~mm}$. The separation from the depression to the focal point of the microstrip coupler, set apart as the microstrip coupler inset, is around $3.757 \mathrm{~mm}$. 


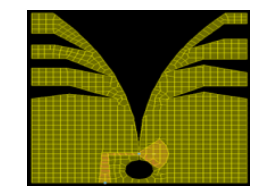

Fig .1: Geometric layout of an antenna

Table 1: Antenna Parameters

\begin{tabular}{|c|c|}
\hline Antenna parameters & Dimension \\
\hline Length of the Antenna & $88 \mathrm{~mm}$ \\
\hline Width of the Antenna & $75 \mathrm{~mm}$ \\
\hline Lobe Height $\left(\mathrm{H}_{\mathrm{f}}\right)$ & $7.09 \mathrm{~cm}$ \\
\hline Lobe Length $\left(\mathrm{L}_{\mathrm{f}}\right)$ & $7 \mathrm{~cm}$ \\
\hline Taper Rate & 0.04 \\
\hline Slot line Length $\left(\mathrm{S}_{\mathrm{L}}\right)$ & $1.5 \mathrm{~mm}$ \\
\hline Flare Diameter $\left(\mathrm{C}_{\mathrm{d}}\right)$ & $10.3 \mathrm{~mm}$ \\
\hline Slot line Width & $0.5 \mathrm{~mm}$ \\
\hline Back Wall Offset $\left(\mathrm{L}_{\mathrm{o}}\right)$ & $1.6 \mathrm{~mm}$ \\
\hline Ratio of the Slotted to Non-Slotted area & $46: 44$ \\
\hline Length of the Coupler $\left(\mathrm{L}_{\mathrm{c}}\right)$ & $12 \mathrm{~mm}$ \\
\hline Width of the Coupler & $1.5 \mathrm{~mm}$ \\
\hline
\end{tabular}

\section{Mathematical Expression}

\section{Equations}

The exponential taper curves of the Vivaldi antenna is defined by,

$$
x=C_{1} e^{R z}+C_{2}
$$

Where,

$$
\begin{aligned}
& C_{1}=\frac{x_{2}-x_{1}}{\left(e^{\left.R z_{2}-e^{R z_{1}}\right)}\right.} \\
& C_{2}=\frac{x_{1} e^{R z_{2}}-x_{2} e^{R z_{1}}}{\left(e^{R z_{2}}-e^{R z_{1}}\right)}
\end{aligned}
$$

The end points of the flare are $\left(\mathrm{X}_{1}, \mathrm{Z}_{1}\right)$ and $\left(\mathrm{X}_{2}, \mathrm{Z}_{2}\right)$. The end of the flare has a cavity with diameter $C_{d}=10.3 \mathrm{~mm}$.

The cavity is adjusted by the equation:

$C_{a}=0.5 C_{d}-0.5 C_{d}(\cos \theta)$

Where,

$\theta=\sin \left(\frac{S_{w}}{C_{d}}\right)$

The cut off frequency of an antenna can be determined by the equation

$$
f_{c}=\frac{c}{\left[w^{\prime} \sqrt{\left(\varepsilon_{r}\right)}\right]}
$$

Here, $\mathrm{c}-$ Speed of light $f_{r}$-Resonant frequency $\varepsilon_{r}-$ Relative permittivity $\mathrm{w}$ - width of the flare

\section{Parametric Analysis}

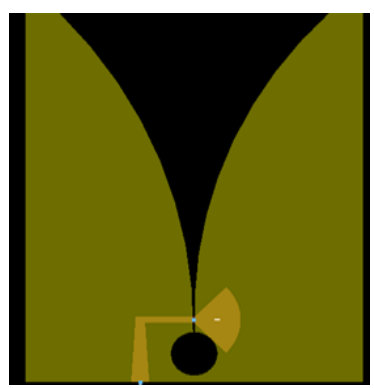

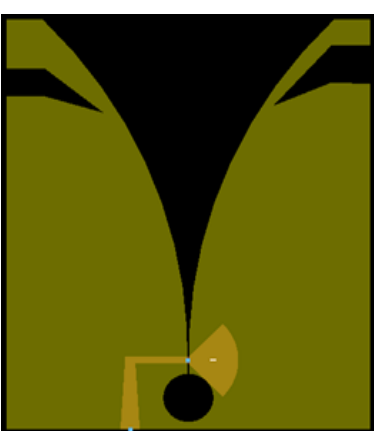

(b)

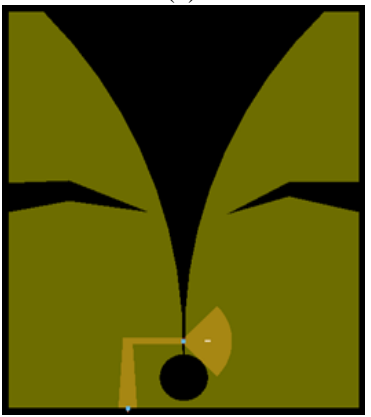

(c)

Fig. 2: Antenna Layout (a) Without slot, (b) upper slot, (c) Lower slot

The figure. 2 shows the antenna layout for Without slot, Upper slot, and Lower slot. The effect of the slots shows the performance of an antenna. For effective coupling the opening is limited towards one end to gadgets, for example, blender diodes. The reception apparatus is edged on Rogers RT/duroid 5870 substrate with the thickness of $1.57 \mathrm{~mm}$. For including the decreased spaces, it is important to experience the accompanying advances. At first, the extraneous part of the electric-field circulation in the decreased opening which is alluded as the gap dispersion, is acquired. In the subsequent stage, far fields gets emanated by the identical attractive current in the spaces are set up. The nearness of the dielectric is represented the determination of the gap appropriation. At second step, the opening conveyance gets disregarded. The opening conveyance in the decreased space is dictated by utilizing the typical voyaging wave reception apparatus expecting that the gap dissemination is represented overwhelmingly by the proliferating modes comparing to the non ended structure. By changing the emanating blade, the pick up of a reception apparatus increments altogether at the working recurrence.

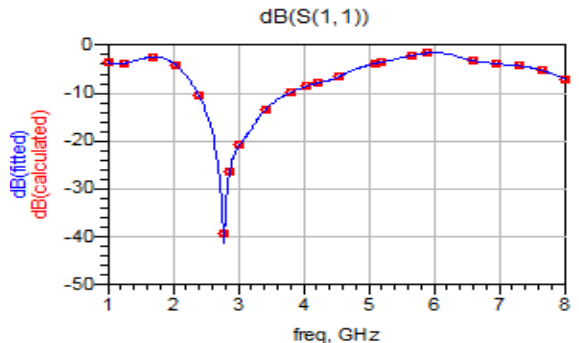

(a)

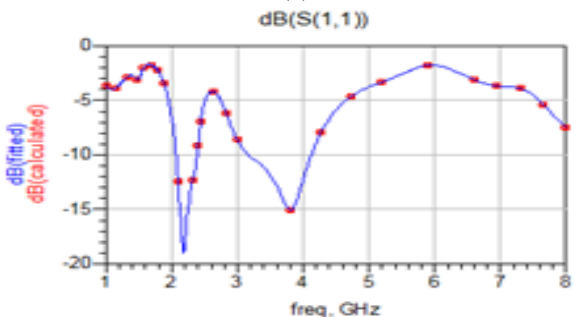

(b) 


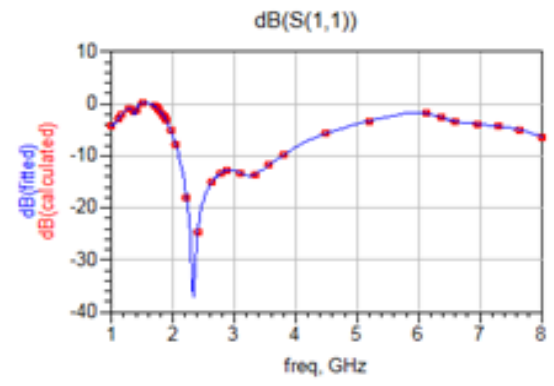

(c)

Fig. 3: Simulated Results (a) Without slot, (b) Upper slot (c)Lower slot

The figure (a) displays the without slot structure, the return loss $\left(S_{11}\right)$ defines the operating frequency at $2.8 \mathrm{GHz}$. As observed from the reproduced result the arrival misfortune esteem is not exactly $-43 \mathrm{~dB}$ at recurrence $2.8 \mathrm{GHz}$.At this working recurrence, the pick up of a reception apparatus is expanded by $4.6 \mathrm{~dB}$ and the result of directivity is $4.6 \mathrm{dBi}$ with the successful edge of 4.3 steradians. The power is transmitted along the layer with 0.009 watts and its greatest force is accomplished with 0.002 watts/steradians. Spaces are presented in light of the fact that it can be mounted to any surface. By extra openings the execution of a radio wire is examined so an upper space is presented in figure (b). The arrival misfortune (S_11)of an upper opening characterizes that the upper recurrence is moved over the bandgap from 2.2-3.8 GHz. It has the ability to work inside the bandgap of working recurrence, the pick up of a radio wire is $4.7 \mathrm{~dB}$ and is given by the comparable directivity. The most extreme force brings about 0.002 watts/steradians. As observed from the figure the aftereffect of the arrival misfortune is not exactly - 19dB.The pick up is expanded altogether because of transmitting balances of a radio wire. By including an another opening at the lower end, figure (c) shows the recurrence in which it works adequately. The arrival misfortune ( $\mathrm{S}$-11) characterizes the entire range at 2.4GHz.As seen from the mimicked result, the arrival misfortune is not exactly $-40 \mathrm{~dB}$ at recurrence $2.4 \mathrm{GHz}$. It is seen at this specific recurrence the pinnacle pick up of around $2.1 \mathrm{~dB}$ with directivity esteem as $3.5 \mathrm{dBi}$ is gotten. The directivity is not as much as the pinnacle pick up an incentive in $2.4 \mathrm{GHz}$ of working recurrence. The viable point is characterized with 5.512 steradians and the resultant power is emanated by 0.006 watts with its most extreme force of 0.001 watts/steradians. At the point when contrasted with all the three openings, by including a decreased space the reception apparatus parameters change as per the working recurrence. It is seen that the pinnacle pick up is expanded essentially at all the three structure because of the adjustment of the transmitting balances. It conspicuously influences the radio wire pick up and proficiency. Thus because of concealment of undesirable surfaces, the current emanates vertically and it improves the electrical length lastly it produces more grounded mandate radiation. From these investigation, it is tentatively checked that the decreased opening reception apparatus bolsters bigger data transmission and it has the ability to produce the ISM band of frequencies.

\section{Results and Discussion}

In all cases, computations were done using both simulated and measured results and are captured by Agilent Momentum Visualization viewer in Key sight ADS 2013.06. When compared to all the three slots, the performance of the six slotted Vivaldi antenna is more efficient. It supports over the band of frequencies from 1.8 to $2.4 \mathrm{GHz}$, the return loss is $-30 \mathrm{~dB}$. The antenna gain is $4.5 \mathrm{~dB}$ which is similar as directivity. Effective angle is 4.3 steradians. The power radiated from an antenna is 0.062 watts with Maximum intensity as 0.014 watts/steradians.

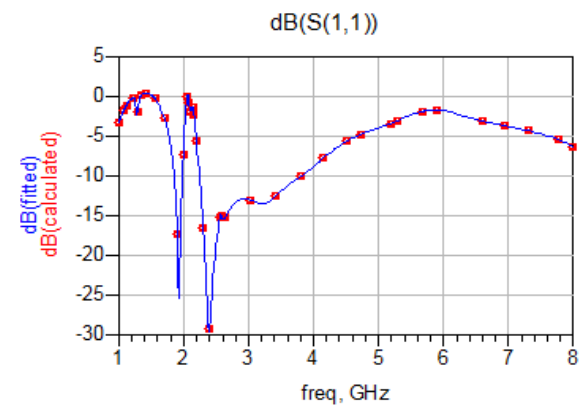

Fig.4: Simulated result of six slotted antenna

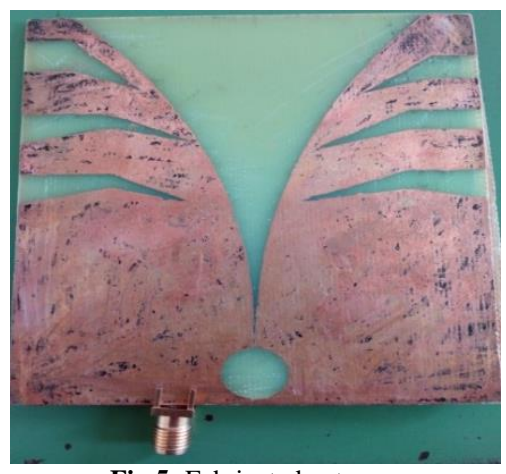

Fig.5: Fabricated antenna

The figure displays the fabricated six slot Vivaldi antenna with substrate named as Rogers RT/duroid 5870. By comparing the measurement results of without, lower and upper slots, it is observed that the six slot tapered antenna is more effective for detecting tumorous breast tissue .

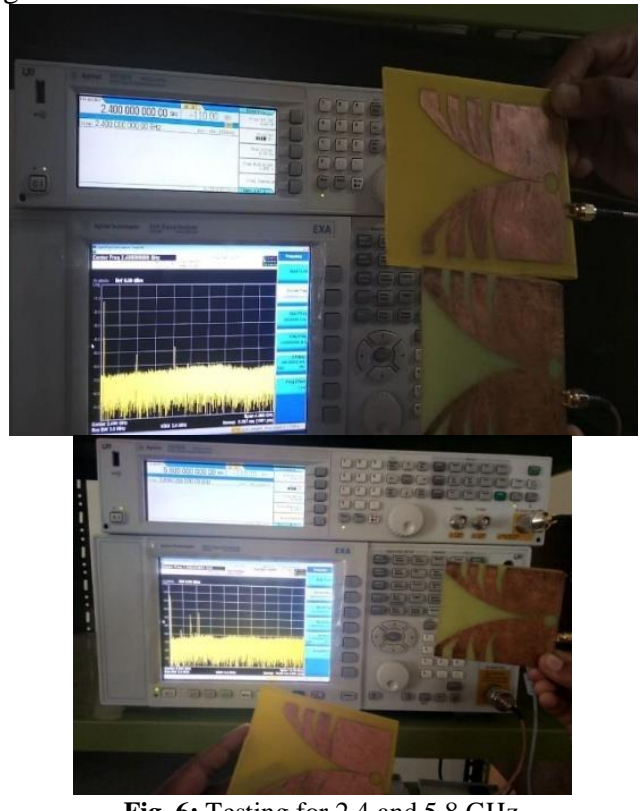

Fig. 6: Testing for 2.4 and $5.8 \mathrm{GHz}$

The Vivaldi Antenna additionally designed to support above 5 GHz. This frequency variation is employed for Wi-Max applications. 


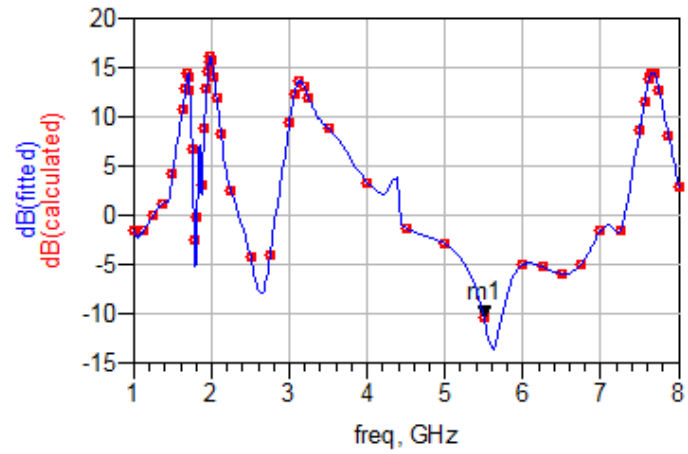

Fig. 7: Simulation result for WIMAX application

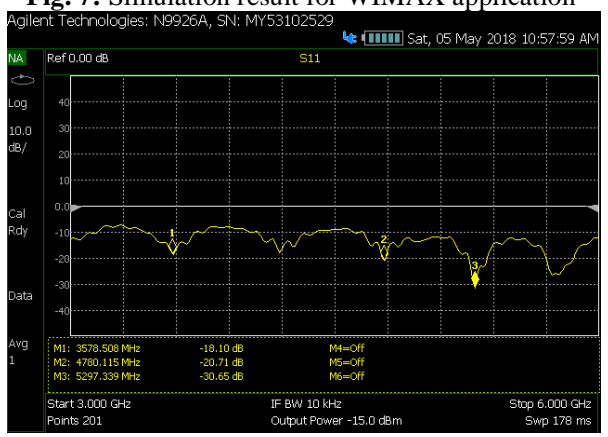

(a)

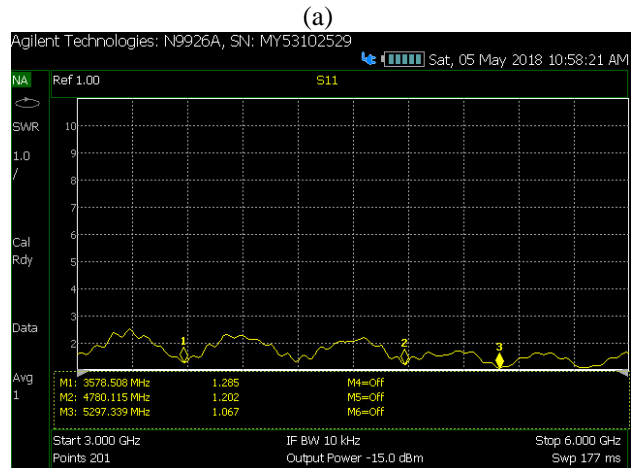

(b)

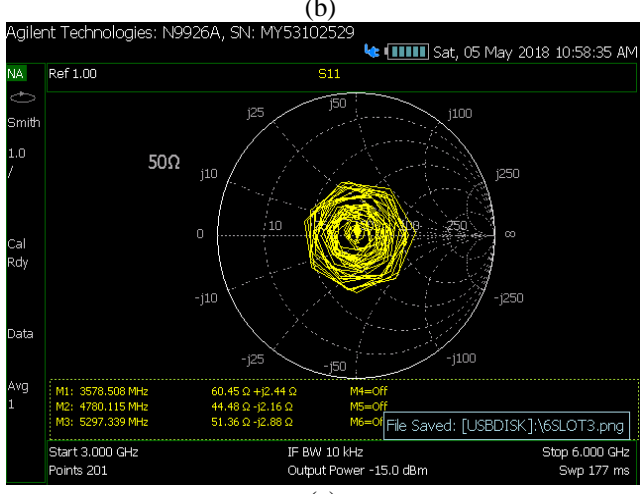

(c)

Fig. 8: (a) Measured Output, (b) SWR, (c) Smith Chart.

From the Figure.6, The Fabricated antenna is connected to Agilent N5171B 3GHz EXG_ Analog Signal Generator is used to generate the signal to transfer the frequency between 1.8 to 2.4 $\mathrm{GHz}$ with air as a medium. The transferred signal gets analyzed and the required frequency is received by Agilent N9010A $26.5 \mathrm{GHz}$ EXA_ Signal Analyzer and similarly tested for 5.8GHz.[15]

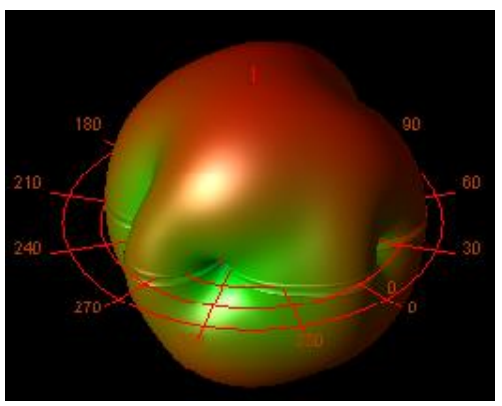

(a)

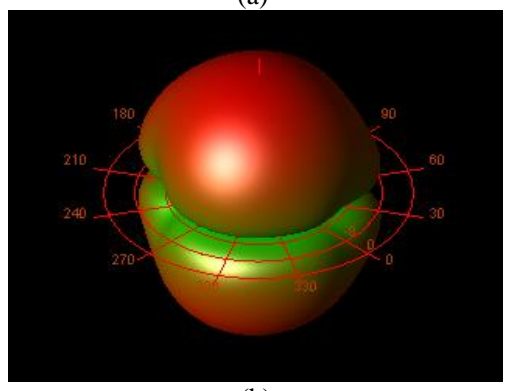

(b)

Fig. 9: (a) Radiation Pattern (2.4GHz), (b) Radiation Pattern $(5.8 \mathrm{GHz})$.

Resonator can be connected to a $50 \Omega$ SMA due to the proper selection of $50 \Omega$ feed. It is desirable to have a radiation characteristics and to facilitate successful designs of an antenna. [16]

\section{Conclusion}

A design of UWB Vivaldi antenna is optimized to achieve enhanced performance for biomedical microwave imaging. The fabricated antennawas designed, built, and tested to meet the defined specifications. There was great success in finding a suitable structure, the development of an Vivaldi antenna for $2.4 \mathrm{GHz}$ as the ISM band which is used for breast phantom measurement. It showed promising simulation results for performance and construction feasibility. However, the results acquired show that the simulated result supports 1.8 to $2.4 \mathrm{GHz}$ and $5.6 \mathrm{GHz}$ which is suitable for microwave imaging applications and Wi-Max Applications and it agrees well with the measured result. The prototype antenna is tested successfully using Agilent N5171B 3GHz EXG_Analog Signal Generator and Agilent N9010A 26.5GHz EXA_Signal Analyzer. By placing the dielectric material having the dielectric property similar to breast tumorous tissue in air medium can be realized and tuned. So this antenna is suitably used for microwave breast phantom technique.

\section{References}

[1] Balanis CA, Antenna Theory, 2nd ed. New York: John Wiley \& Sons, Inc., (1997).

[2] Kun M, Zhi QZ, Jiang NW, Mubarak SE \& Zai PN, “A Printed Vivaldi Antenna with Improved Radiation Patterns by Using Two Pairs of Eye-Shaped Slots for UWB Applications", Progress In Electromagnetics Research, Vol.148, (2014), pp.63-71.

[3] David CG, Jeremie B \& Elise CF, “Antenna Calibration Method for Dielectric Property Estimation of Biological Tissues at Microwave Frequencies", Progress Electromagnetics Research, Vol.158, (2017), pp.73-87.

[4] Heena C, Romika C \& Ashish V, "Design and Analysis of Circular Patch Micro Strip UWB Antenna for Breast cancer Detection", International Journal of Innovative Research in Science Engineering and Technology (IJIRSET), (2015).

[5] Chan HS, Raed AAA, Siau WJC, Dawei Z, Hussain AA \& Peter SE, "The Design of a Resistively Loaded Bowtie Antenna for Applications in Breast Cancer Detection Systems", IEEE Transactions on Antennas and Propagation, Vol.60, No.5, (2012). 
[6] Bah MH, Hong J, Jamro DA, Liang JJ \& Kponou EA. Vivaldi antenna and breast phantom design for breast cancer imaging. IEEE 7 th International Conference on Biomedical Engineering and Informatics (BMEI), (2014), pp.90-93.

[7] Samira A, Thuraiya AR, Khalid A and Sreelakshmi TG, "Development of Antenna for Microwave Imaging Systems for Breast Cancer Detection", J Mol Imag Dynamic, an open access journal, (2013).

[8] G Ainabekova, Z Bayanbayeva, B Joldasbekova, A Zhaksylykov (2018). The author in esthetic activity and the functional text (on the basis of V. Mikhaylov's narrative ("The chronicle of the great jute"). Opción, Año 33. 63-80.

[9] A Akhmetbekova, P Auyesbayeva, Sh Ibrayev (2018). Turkic "Hikaya" genre and its characters. Opción, Año 33. 81-106.

[10] Maria K, Irene SK, Constantine GK, Evangelos G, Christophe C, Nadine J \& Bernard D, "Evaluation of a Tumor Detection Microwave System with a Realistic Breast Phantom", Microwave and optical technology letters, Vol.59, No.1, (2017).

[11] Rajesh N, JithilaVG, Malathi K, Livya L, Balaji M, Dinesh BR \& Mohammed GNA, "Modified Antipodal Vivaldi antenna for ultrawideband communications", IET Microw. Antennas Propag., (2016), pp.1-5.

[12] Jingjing Z, Elise CF \& Ronald HJ, "Cross-Vivaldi Antenna for Breast Tumor Detection", Microwave and Optical Technology Letters, Vol.51, No.2, (2009).

[13] Meena AJK \& Kabilan AP, "Modeling and simulation of Microstrip patch array for smart antennas", International Journal of Engineering-IJE, Vol.3, No.6, (2010), pp.662-670.

[14] Alias Jeyanthi DKM, Thangaselvi E \& Prianga AS. Simulation of Rectangular Microstrip Patch Antenna Using Nylon Fabric Material. PSNA College of Engineering \& Technology, Dindigul, Tamil Nadu, India, Vol.3, No.1, (2013), pp.645-647.

[15] Magthoom FY \& Meena alias Jeyanthi K, "Design of a Novel Microstrip Patch Antenna for Microwave Imaging Systems", International Journal of Engineering and Technical Research (IJETR), Vol.2, No.3, (2014).

[16] Hsieh HW, Lee YC, Tiong KK \& Sun JS, "Design of a multiband antenna for mobile handset operations", IEEE Antennas and Wireless Propagation Letters, (2009), pp.200-203. 